\title{
Conflicts of Interest in the Roles of the University Professor
}

\author{
Stephen D. Sugarman*
}

American universities are increasingly proactive in dealing with conflict of interest problems of their faculty. Changing social norms, publicized scandals, and more have made both university administrators and faculty extra alert to the dangers of faculty infidelity to their roles as teachers and scholars. Personal interests - both financial and non-financial - appear increasingly to pressure faculty to behave inappropriately. Most faculty members resist those pressures. Yet, enough conduct that either is, or appears to be, improper has occurred to prompt the adoption by universities of an ever-more complex regulatory regime. This regime no longer relies primarily upon threats of after-the-fact punishment for gross deviations from professorial norms. Instead, universities have also enacted a wide array of in-advance restrictions. These include required disclosures by faculty members of certain private interests, prohibitions of specific faculty behavior, and specified instances in which faculty members must temporarily withdraw from their professorial roles in light of their private interests. This article draws especially upon the author's experience at the University of California to illustrate the new system of regulation.

* Agnes Roddy Robb Professor of Law, UC Berkeley (Boalt Hall). Thanks to Ariel Porat, Lee Friedman, David Kirp, Robert Price, Jasper Rine, Michael Smith, and Jan Vetter, who provided helpful advice and comments. 


\section{INTRODUCTION}

Three core roles of faculty members at research universities are the truthfinding and truth-telling role, the judging role, and the in loco parentis role. In performing these roles, faculty may face several conflict of interest problems.

Research universities and other institutions connected with higher education employ a range of strategies to deal with these faculty conflicts of interest. A passive strategy relies upon faculty self-restraint arising from faculty integrity and faculty concern about reputation. Active interventions include ex post sanctions for infidelity to faculty roles, required abstention, required disclosure, and ex ante restrictions intended to reduce or eliminate the conflict.

Developments in both higher education and society at large help to explain the marked change over the past three decades in the way that universities deal with faculty conflicts of interest.

\section{Three Faculty Roles}

\section{A. The Truth-Seeking and Truth-Telling Role (Research and Teaching)}

One core role of university faculty is to discover new knowledge and develop new ideas and then to convey that knowledge and those ideas to others. This role includes reporting their research and scholarly findings, typically through published scholarship and presentations at scholarly venues. Teaching is, of course, another essential function of university faculty. Performed not only in the classroom, the lab, or in one's office, faculty also teach through their written publications (which describe and critique the scholarship of others), public lectures, and so on.

\section{B. The Fair Judging Role}

A second central role of university faculty involves making fair judgments about the caliber of the academic work of both students and fellow faculty. Faculty judge students when they apply to institutions, majors, and programs, when they are awarded grades or degrees, and when they are recommended for jobs and further education.

Faculty members judge other faculty in the course of the hiring and promotion processes and in connection with the granting of salary increases, 
awards, and honors. In addition, faculty members judge their colleagues through the peer review process that dominates much of academia - in connection with the publication of articles and books, the awarding of tenure, the awarding of competitive grants, and more.

\section{The In Loco Parentis Role}

A third role of university faculty is to help young people (university students) to mature during the transition period when they move from being children sheltered by their family to autonomous adults, and, often, professionals in their own right. In this capacity, faculty members are expected to provide assistance, restraints, advice, etc., for students in ways that serve the students' best interests.

Since the 1960s, American institutions of higher education have been relinquishing much of their in loco parentis role. Controls over where students live and dine, their access to alcohol (and other substances), their access to members of the opposite sex, and the like have been substantially abandoned at most schools. Moreover, many universities appear to have cast aside the role of self-consciously providing affirmative teaching or training by faculty, deans, and other student services personnel about what are proper moral values and morally upright behavior.

Nevertheless, there remains a strong mentoring relationship between faculty and many students, in which students are emotionally and intellectually (and sometimes financially) dependent upon faculty, and in that relationship, vulnerable students relate to faculty as fiduciaries.

\section{Conflict of Interest Problems that Arise in Performing UNIVERSITY FACULTY ROLES}

Faculty members have conflicts of interest when they have personal interests that, if pursued, will be inconsistent with their roles as faculty. These personal interests are often private financial or social interests, but conflicts can also arise in the pursuit of a faculty member's own academic career. Broadly speaking, this problem of conflicting interests is simply an illustration of the more general problem that principals (e.g., employers) have in getting their agents (e.g., employees) to behave as the principals wish they would.

This Part points out conflicts that arise in the performance of each of the professorial roles described above. The list that follows, which is organized in terms of the three roles just set out, is meant to be illustrative, not exhaustive. 


\section{A. As to Truth-Finding and Truth-Telling}

\section{The Other Master Problem}

Faculty members frequently have financial interests in a private company, a part-time consulting career, and/or an ongoing research funding source (whether the source is a private company, a foundation, or a governmental agency). These interests may put pressure on faculty not to be objective or truthful in the carrying out and/or reporting of their research.

At the heart of the truth-finding and truth-telling role is the duty to report promptly one's findings to the public. But because of their own financial interests, faculty may be dishonest in what they say they have discovered and/or how they describe the state of knowledge in their field. They may accept funding for research with truth-diminishing conditions attached - such as censorship by the source of the funding of the reporting of findings or the delay of the reporting of findings for reasons that benefit the funding source. They may also try to profit personally from the commercial exploitation of discoveries they make as professors in ways that are detrimental to the public at large.

\section{The Ideological Blinders Problem}

Because of personal values, a faculty member may be so committed to a particular point of view as to lose objectivity and the commitment to truthfulness in research and teaching. Probably none of us is wholly objective in our teaching and scholarship, no matter how much we try, but we all recognize that there are lines that most of us would consider inappropriate to cross.

\section{The Publish or Perish and Pandering Problems}

Faculty may be dishonest in their scholarship and/or teaching in response to pressures caused by the need to keep their jobs and get ahead in their fields (and, for many, the need to maintain a stream of external research funding).

Plagiarism and falsifying data are obviously two clear examples of misconduct to which some resort in response to this conflict of interest. Other instances of this sort of misconduct are "stealing" someone else's research idea when you learn about it as a confidential grant reviewer and delaying the publication of a submitted manuscript, when acting in the role of reviewer or editor, in order for your own research on the question to be published first.

When positive student evaluations are viewed as essential for obtaining tenure or other academic promotions, faculty may be dishonest (or disingenuous) in their teaching in order to win favorable evaluations. In the 
same vein, faculty may distort what they say in their scholarship because they are pandering to the views of senior faculty in their department who will decide upon their tenure and promotion to full professor status.

\section{The Disloyalty and Slacker Problems}

For personal financial reasons, faculty members may devote too much time to other professional opportunities (e.g., professional consulting or moonlight teaching). Perhaps less problematic, some faculty, for selfish reasons, deliberately undertake writing and teaching efforts that are not the best use of their talents - for example, writing textbooks or popular books that may bring fame and fortune but do not advance the state of knowledge in the faculty member's field. Yet another problem is that some faculty members may only barely meet their teaching and research obligations because of laziness or burn-out.

These conflicts may not specifically lead to dishonesty in the truth-telling role. However, they may result in an inadequate or skewed performance of that role (and perhaps dishonesty when reporting on the level of one's effort). This failure to perform vigorously the truth-telling role is especially problematic in a world of tenured employment and minimal supervision of faculty use of time on a-day-to-day basis.

\section{The Future Opportunity Problem}

Some faculty members move on from their university appointments to other jobs, often either more prominent or higher paying. Professional school faculty may especially have these sorts of opportunities. Aware of these options, faculty may make unjustified scholarly claims or self-censor their scholarly output in ways that those anticipating a career-long life of "academic freedom" would not.

\section{B. As to Judging}

Because of their private interests, faculty may be induced to make biased decisions in their evaluation of academic work, unfairly either favoring or disfavoring the work of another.

\section{The Fondness/Dislike Problem}

Everyone who awards grades, writes letters of recommendation, and the like recognizes that personal fondness (or dislike) of a student (or faculty colleague) may entice a faculty member to judge that person's academic work to be better than (or worse than) it is. Fondness (or its opposite) may arise because of family ties, social ties, and so on. The risk of bias may 
also arise because of the nature of the professional relationship between the judge and the judged.

\section{The Bribery and Shakedown Problem}

Those being judged may try to bribe faculty to be undeservedly favorable to them. Although bribes are typically thought to be financial, in academia they may be of other sorts as well, including sexual or other favors. By contrast, the request for money or other personal benefits may be initiated by the faculty member, creating a shakedown problem. In further contrast, those being judged may try to shake down faculty by threatening them with harm (including, perhaps, harm to their reputation) unless a favorable evaluation is provided.

\section{The Selfishness Problem}

Faculty may put their own academic or outside financial interests ahead of the good of the university (or the wider university community) in their appraisal of applicants for open faculty positions, as well as in their appraisal of grant applications, articles they are peer reviewing, and candidates they are evaluating for other institutions. Ideology, research agendas, methodology, field of expertise, and the like are some of the issues on which faculty may over-weigh their own values because of their own selfish career or financial interests.

\section{As to the In Loco Parentis Role}

Because of their own interests, faculty members may commit something analogous to child abuse or neglect. One example is unfairly using a student to further the faculty member's own research and career goals in ways that are not in the best interests of the student. Another is coercing students to work on consulting projects of the faculty member or to work as teaching assistants for the faculty member when such work is not in the students' best interests.

A faculty member commits a different form of abuse when s/he exploits student dependency and vulnerability for the faculty member's personal pleasure. This includes sexual seduction and harassment. 


\section{How Universities Deal with Faculty Conflict of Interest Problems}

The problem of faculty conflict of interest is not generally handled by criminal law, tort law, or administrative agencies outside the field of education. Instead, it is generally managed by the institutions of higher education themselves - primarily universities, but also, in some cases, those non-university organizations that manage scholarly publications, scholarly conferences, and the awarding of funds for scholarly research.

\section{A. Reliance on Self-Control by Individual Faculty}

1. Reliance on Faculty to Be Faithful to Their Professorial Roles and to Put Aside Personal Interests that May Be in Conflict

Notwithstanding the temptations of personal interests, most faculty members, as a matter of self-identity, choose to put their personal interests aside when they are in conflict with their duties as faculty members. Even without formal constraints, they would voluntarily try to adhere to what they see as the norms of the profession and strive to be faithful to the roles of university faculty. Faculty members probably adhere to these norms, at least in part, because of what they learn through observation when they are students and what they see as the conduct of their more respected senior faculty colleagues.

Universities and other organizations of higher education understandably rely upon the integrity of faculty both because "integrity" is a value that is sonorous with the ideals of the university itself and because this strategy has no enforcement costs. Indeed, in the past, universities relied heavily on this passive strategy. The costs of this approach come in the form of the failure of self-control.

2. Reliance on the Self-Control that Arises out of the Concern Faculty Have for Their Reputations

Most people appear to care about their reputations, and this is probably especially true of university faculty, who are generally very eager to command the respect of their students, colleagues, and peers in other institutions. Because their reputations can be influenced by how their performance of the key faculty roles discussed here is perceived, the selfish concerns of faculty members can induce them to be faithful to their faculty roles even where personal morality alone would not suffice to avoid the temptations of conflicting personal interests. 
The concern for reputation cuts across all the faculty roles. If you are thought to abuse students, if you are thought to be unfair (or unreliable) in judging academic work, and/or if you are thought to be unreliable in your scholarship, then these beliefs can reduce both your general reputation, as well as your specific reputation within different communities.

Moreover, even if fear of a bad reputation fails to control faculty conduct, the dissemination of a deservedly bad reputation may cause others to avoid connections with, or reliance upon, the faculty member who risks harm to them.

As with reliance upon faculty "integrity," there are no administrative costs attached to passively relying upon faculty members' concern for their reputations as a mechanism to promote fidelity to the faculty role in the face of conflicts of interest. And just as with relying on integrity, the costs of relying on reputational concerns come in the failure of self-control.

\section{B. Imposing External Controls}

Some faculty members have precious little moral commitment to being faithful to their faculty roles and care little about their reputations. Others find the temptations of personal interests too great and succumb to them, notwithstanding concerns they may have about their reputations. For these and other reasons, universities have never relied exclusively on faculty self-control to deal with conflict of interest problems.

\section{Threat of After-the-Fact Punishment}

The traditional approach adopted by universities was simply to warn faculty members, in general terms, that they face the risk of punishment by the university if, when presented with a conflict of interest, they act in furtherance of their personal interest and are decidedly unfaithful to the relevant faculty role. This is a kind of general deterrence strategy that may be thought of as analogous to the way that tort law threatens people with an after-the-fact penalty if they unreasonably violate their duties (although, in the university setting, perhaps the conduct that triggered sanctions more conventionally had to rise to the level of gross negligence).

This approach of course requires some mechanism by which the university can learn of faculty violations of duty. Because most faculty members who work at research universities have a great deal of discretion in the way they carry out their jobs, detection of infidelity to the core faculty roles can be very difficult. This problem is exacerbated because the faculty misconduct at stake here does not always involve individual victims who can blow the whistle, and, furthermore, certain sorts of victims are not likely even to 
realize that they are victims. Finally, as will be reemphasized below, if the deterrent threat fails, misconduct occurs, and penalties must be imposed, this can bring extremely unwelcome publicity to the institution involved.

Perhaps in part because of these shortcomings of a regime of vague threats of ex post punishment, in more recent years universities and related bodies have adopted a proliferation of more precise requirements designed to better manage the conflict of interest problem. Frequently, these new regulations have been imposed on faculty because of a specific event or scandal to which higher education administrators are responding.

\section{Requiring Abstention}

One way to preclude a conflict of interest is to require the faculty member who would have the conflict to abstain from performing the relevant faculty role in the first place. This might mean not judging a certain student or fellow faculty member's work, not mentoring a certain student, not teaching a certain course or topic, perhaps even not undertaking research on a certain topic.

Of course, abstention has its costs. Faculty members who are hired to do certain things are then excused from doing them. Clearly, abstention must be exceptional. Hence, abstention as a control mechanism seems inevitably restricted to situations in which the conflict is perceived as most acute.

Abstention may be triggered in a variety of ways. For example, a substantive rule may require faculty to withdraw in a specified situation. Or a faculty member may be required to submit the matter to a review process so as to obtain a third-party determination as to whether abstention should occur in that instance. Parties being judged might be empowered to trigger abstention, perhaps merely by (selectively) ruling out some judges or else by bringing concerns before a third-party process. These variations carry with them different administrative costs, different risks of unnecessary abstention, and different risks of abuse by those seeking abstention. Moreover, some additional mechanism must be in place to deal with the failure of faculty to abstain when they should have done so.

\section{Requiring Disclosure}

Requiring the disclosure of relevant information is another way of dealing with faculty conflicts of interest. The facts disclosed may then be taken into account in appraising the faculty member's fidelity to the relevant role. Disclosure can also lead to further investigation, when the initial disclosure does not make evident whether there is a conflict of interest or when the initial disclosure suggests that more information is needed to determine whether the faculty member has been faithful to the relevant role. 
Furthermore, requiring disclosure can prompt faculty to proactively avoid situations in which the information disclosed would be found unseemly or suspect by others.

Disclosure schemes have their own distinctive costs. They may be seen to invade unnecessarily people's privacy (depending in part on how public the required disclosure is). There are also administrative costs to operating a disclosure scheme. And as with abstention, some supplementary mechanism is required to punish the failure to make required disclosures. Furthermore, disclosure by itself may well not prevent infidelity to the relevant faculty role.

\section{Imposition of Regulatory Supervision (an Ex Ante Regime)}

Institutions with which university faculty are affiliated increasingly establish restrictions on what faculty may do in their professional and personal lives as a way of reducing conflicts of interest in advance. Examples will be given below of regulations intended to restrict a faculty member's own interests so as to reduce the risk that a conflict of interest arises.

One cost of trying to preclude in advance the creation of conflicts of interest is the decision by some not to serve in the faculty role. While of course there are throngs clamoring to be university professors, the concern here is illustrated by instances in which cutting-edge inventors, whom universities would like to retain as professors, leave their jobs for other employers because university policies allow no satisfactory accommodation of faculty members' desire for economic gain through the commercial exploitation of inventions.

Another cost of ex ante prohibitions stems from their over-inclusiveness. For example, genuinely loving relationships between faculty and their graduate students (long a source of faculty spouses) may be precluded by broadly cast rules based on fears of exploitation and favoritism. And, again, the university must be prepared administratively to deal with those who violate the ex ante prohibition.

\section{Some SPecific Examples DraWn LaRgely from The UNIVERSITY OF CALIFORNIA EXPERIENCE}

In order to make more concrete the conflict of interest control mechanisms just discussed, specific examples of these mechanisms will be described next based upon the author's experience at the University of California ("UC"). 


\section{A. Examples of Abstention}

\section{Judging Faculty}

At the University of California, candidates for tenure (or promotion to full professor) are entitled to request that certain referees be disqualified from judging their work. ' Candidates are asked to provide reasons for the challenge, such as personal conflicts they have had with someone or scholarly disputes they have had with a potential referee. This does not give the candidate a formal veto, but, at UC Berkeley, it appears that requests not to involve, say, one or even a few people in the review of a candidate's case are honored. ${ }^{2}$

Recently, UC Berkeley has encountered attempts to disqualify entire departments (or units within departments) from participating in decisions to grant or deny tenure, on the ground that the research or ideological bent of the unit as a whole makes a fair appraisal of the candidate's work impossible. These are extremely difficult and delicate matters because the candidate may, deliberately or not, be seeking to remove those who are academically best-suited to evaluate his or her work.

If a faculty member's spouse is seeking a position on the same faculty, it is generally understood at UC Berkeley that the current faculty member is to abstain from participating in the process by which the applicant spouse is evaluated. (This notwithstanding, it is generally thought quite appropriate for the existing faculty member to condition his or her remaining with the university on the appointment of his or her spouse - even if this results in the hiring of someone who would otherwise not have been.)

\section{Judging Students/In Loco Parentis}

UC has recently adopted an official policy that faculty may not evaluate the work of students with whom they have romantic or sexual relationships. ${ }^{3}$ Some of the pressure in favor of this policy came from those who fear that a break-up of a romantic relationship during the period that the student is providing academic work for the faculty member could lead to adverse consequences for the student, as well as the worry that a student fearing such consequences might be dissuaded from breaking off the romantic relationship. In short, concerns about both favoritism and its opposite were relevant to the adoption of this policy.

1 U. Cal., Academic Personnel Manual $\S 100,220-80 \mathrm{c}$, available at http://www. ucop.edu/acadadv/acadpers/apm/welcome/html [hereinafter APM].

2 This and subsequent unreferenced examples and comments draw upon the personal experience of the author.

3 APM, supra note $1, \S 015$. 
This new policy, in effect, formally extends what appears to be only an informal policy that has long applied with respect to children and spouses.

\section{B. Examples of Disclosure}

\section{Truth-Telling/Research}

UC requires faculty to seek funding for their research through their home campus. ${ }^{4}$ This serves to put administrators at the institution on notice as to who is funding the research. Moreover, UC further requires that, for grants sought through the university, faculty must disclose whether they have consulted for the funding source or have financial interests in the funding source. ${ }^{5}$ If a disclosure is made, then a special independent review of the proposed grant occurs through which it is determined whether the conditions of the grant and the relationship between the faculty member and the funding source are such as to make it inappropriate for the grant to be accepted. (Nationally, concerns have recently been expressed that those faculty members who typically serve on these sorts of review committees themselves often have outside financial interests that may make them biased in the performance of their committee roles.) At UC Berkeley it appears that these reviews rarely result in a requirement that the faculty member refuse the grant; sometimes, however, the faculty member is required to alter his or her financial connection with the grant source.

In addition, although UC does not appear officially to require it, the strong professional norm among UC faculty is to disclose the source(s) of funding of their research when they publish their research findings. Indeed, this disclosure is increasingly required by the journals in which articles are published.

In this same vein, in some fields, it is increasingly the professional norm to disclose relevant personal financial ties the researcher has when making an oral presentation of research at a conference or other scholarly venue.

\section{Truth-Telling/Loyalty}

UC faculty are required to disclose all their inventions, even if they claim those inventions were not made in their role as a faculty member. ${ }^{6}$

$4 \quad$ Id. $\S 190$; see also id. $\S 025$.

$5 \quad$ Id. $\$ 028$.

6 See U. Cal., Guidance for Faculty and Other Academic Employees on Issues Related to Intellectual Property and Consulting, at http://www.ucop.edu/ott/consult.html (July 2004); U. Cal., Patent Policy (Sept. 1997), available at http://www.ucop.edu/ ott/patentpolicy/patentpo.html. 
Elaborate procedures exist for determining whether the university has a claim to the financial benefits of disclosed inventions - a process that is primarily concerned with whether university facilities were used and whether the work done was within the scope of university employment.

\section{Judging Faculty}

It is a strong norm among faculty at $\mathrm{UC}$, when providing peer review, to disclose important past professional connections with the faculty whose work is being evaluating, say, for tenure or for publication or for funding (provided, of course, that the faculty member doing the reviewing is aware of who the author is, which is sometimes not the case when there is anonymous peer review of manuscripts submitted for publication or of proposals submitted for funding). Faculty members are routinely reminded of this norm when evaluations are sought by being specifically asked to disclose connections with the person whose work is being reviewed.

\section{Examples of Ex Ante Regulation}

\section{Truth-Telling/Research}

At UC San Francisco, faculty members in certain research units are not allowed to take research funding from tobacco companies. This has been justified, at least in part, by claims and beliefs that tobacco companies have been too intrusive into the university research they have funded and have thereby compromised the disclosure of findings adverse to their business interests.

At UC Berkeley there was a much publicized internal fight over whether faculty (in plant and microbial biology) would be allowed to accept research funding from a large pharmaceutical enterprise. In the end, over considerable opposition, a close funding tie to that enterprise was eventually agreed to, with conditions attached that were designed to protect faculty autonomy.

\section{Truth-Telling/Loyalty}

Some universities, although not UC, require faculty to disclose (perhaps confidentially to a designated internal administrator) who their consulting clients are. For its part, UC has recently adopted a policy that puts specific limits on the number of days each academic year that faculty may engage in paid consulting in their field (essentially an average of one day per week) - with no limit placed on the amount of income that may be earned and no requirement that client names be disclosed. ${ }^{7}$ This regime 
was enacted in response to a controversy in which some faculty appeared to be selling altogether too much of their "time" to funding sources outside of the university. To police this new policy, UC requires annual certification of compliance with it along with a disclosure of the number of days of outside consulting that were provided.

This same policy also presumptively prohibits faculty from teaching elsewhere and from serving in executive or management positions in enterprises (although in individual cases exceptions to these prohibitions may be granted).

\section{Truth-Telling/Teaching}

The UC Faculty Code of Conduct provides that it is a violation for faculty as teachers to permit the "significant intrusion of material unrelated to the course." At UC this limitation as to what one may teach about is somewhat hedged in by the requirement that course content (including a description and syllabus) must be approved in advance by the Committee on Courses of Instruction on each campus. ${ }^{9}$

Notice that this requirement does not specifically bar inappropriate propagandizing in the classroom. As to that, the very recently adopted UC policy on Academic Freedom ${ }^{10}$ makes clear that faculty are entitled to tell their students their own professional opinions about relevant matters, but that in doing so they are to be guided by appropriate professional norms, which surely make inappropriate the practice of mere propagandizing. In this connection, the UC Faculty Code of Conduct generally states that it is a violation to make "use of the position or powers of a faculty member to coerce the judgment or conscience of a student." 11

The policing of actual teaching content appears to be left to a combination of faculty self-control plus mechanisms by which students enrolled in the course might complain. The latter includes both the informal student grapevine and the comments students may provide as part of the formal student course evaluations that are required for every course and that must be prepared and collected under conditions that permit student candor and assure that all evaluations reach department chairs or deans.

$8 \quad$ Id. $\S 015$.

$9 \quad$ Id. $\S 005$.

10 ld. $\$ 010$.

11 Id. $\S 015$. 


\section{Judging Students}

In some units at UC, including the Law School at UC Berkeley, student exams must be graded in ways that ensure that faculty are generally unaware of whose exam it is. However, this appears to be an uncommon practice at UC generally.

\section{In Loco Parentis}

$\mathrm{UC}$ has recently adopted a policy that forbids faculty from having a romantic or sexual relationship with their own current students (or students they are likely to teach in the future). ${ }^{12}$ The impetus behind the adoption of this policy was a widely publicized report of an alleged sexual involvement between a prominent administrator and a student.

\section{Examples of Ex Post Punishment}

\section{Truth-Telling/Research}

One UC faculty member appears to have recently resigned for having submitted a grant application based upon someone else's grant application to a different funding source, after the faculty member learned about the other application while serving in the role of reviewer. This is an example of conduct that violates the general provision of the UC Faculty Code of Conduct that deems unacceptable the "violation of canons of intellectual honesty, such as research misconduct and/or intentional misappropriation of the writings, research and findings of others." ${ }^{13}$

\section{Truth-Telling/Loyalty}

So that possible slacking or other reasons for lack of scholarly productivity as a faculty member do not go unnoticed, it recently has become mandatory at UC that a faculty member's work, even someone with tenure, be formally evaluated at the campus level at least every five years. ${ }^{14}$ In principle, someone who is identified in the course of this review as not performing the required faculty roles could become subject to negative sanctions, tenure notwithstanding. Whether formal sanctions have actually been imposed at UC for gross underperformance of one's faculty duties is not clear, but it does appear that this five-year review process has stimulated some deans and chairs to act to ease individual non-performing faculty into early retirement. 


\section{Judging Students}

The UC Faculty Code of Conduct states as a general matter that it is impermissible for improper considerations to influence the evaluation of student work..$^{15}$ In this connection, not long ago a UC faculty member appears to have been suspended without salary for a period of time for certifying that two student athletes successfully completed the work required for his course, when this did not actually occur and the faculty member had initially misrepresented the facts.

\section{E. Examples in which It Appears that Only Self-Policing and the Concern of Faculty for Their Reputations Are Relied Upon}

\section{Judging Students and Faculty}

Faculty writing letters on behalf of their students seeking jobs, grants, further educational opportunities, etc., routinely disclose that the applicant is/was one of their students. Despite the concern that favoritism may lead to puffing or worse, recipients of those letters are often eager to hear from the supervising faculty who know the student's work the best. In the end, faculty integrity and concern for reputation are relied upon to assure reasonably honest evaluations.

This conflict of interest problem is also addressed at UC and elsewhere by practical measures designed to minimize the likelihood that a judgment about someone turns on the views of only one reviewer. Indeed, many believe that the peer review system, which is ordinarily based on obtaining evaluations from multiple reviewers, can best expose faculty who are inappropriately praising (or criticizing) - or perhaps have poor judgment altogether.

\section{In Loco Parentis}

The problem of faculty abusing graduate students by having them do things that further the faculty member's own research to the detriment of the student seems to be largely dealt with at UC by assuming proper faculty conduct in general and expecting that violators become known in the department, hoping that this will cause them to lose desirable graduate students to supervise in the future and thereby curtail the problem. 


\section{The Changing Regulation of Faculty Conflict of Interest Problems in Research Universities}

In the early 1970 s (when the author became a professor at UC Berkeley) faculty conflict of interest problems seem to have been managed by a combination of reliance on faculty self-monitoring and the threat of individual after-the-fact punishment if faculty were grossly unfaithful to their roles as truth-tellers, judges, and mentors.

Today, by contrast, at least at UC, the University has adopted a much more elaborate system for dealing with faculty conflicts of interest. First, as just illustrated, there are many specific ex ante prohibitions that seek to prevent (or minimize or at least reduce) conflicts of interest arising in certain specific ways. Second, as also noted above, rules requiring abstention and disclosure now exist. Little, if any, of this regulation was in place thirty years ago.

In contrast to the old regime, which was described above as analogous to tort law, today's regime is much closer to a system of complex government agency regulation, and, in particular, the type of regulation in which certain behaviors are, in advance, specifically identified as required or forbidden.

Why has this shift happened? A number of explanations might be offered. Some of these explanations are not unique to the university setting. Moreover, regulation generally is much more pronounced today in many aspects of life than it was, say, before the 1970s. Hence, this change in the regulation of faculty may be seen as illustrative of a broader trend. Nonetheless, several specific changes in university life are worth emphasizing.

First, although the economic power of a few superstar faculty members may be greater than ever, in many respects the relative power of individual university faculty members is less than it was in the past. Previously, faculty authority over students was much more wide-sweeping and unchallengeable; tenured faculty had analogous power over untenured faculty; and individual faculty generally had far more autonomy over their own fiefdoms. Neither chairs or deans nor even higher-level university administrators sought (or dared) to intrude too deeply. Now this is all changed.

The due process revolution and analogous developments came to the college campus, and they have decidedly empowered students and junior faculty. Egalitarian norms have also allowed those subject to faculty authority to characterize as abuses of faculty roles some conduct that, in the past, in an era of other social norms, may have seemed quite tolerable. At the same time, increased bureaucratization in universities (which, itself, has come about for many reasons) has brought with it more centralization of various 
functions, and at UC, at least, faculty senate groups have willingly approved of much of that centralization. All of this has made faculty conduct in general much more subject to scrutiny, thereby making increased conflict of interest regulation feel almost natural.

Second, the market has intruded into faculty life in ways that were much less common in the past. ${ }^{16}$ For one thing, the opportunity for faculty to make a lot of money on top of their faculty salary has expanded enormously for some faculty in certain fields and has brought with it a combination of university desire to share in the spoils, a heightened concern that moneymaking opportunities increasingly threaten faculty fidelity to traditional roles, and perhaps some jealousy-prompted concerns by faculty who do not have those opportunities that some colleagues are abandoning their faculty roles. In this respect, faculty role models may also be very different from the past. Instead of the darlings of the department being the "pure" scholars of old, in many places they are now the "entrepreneurs," the "greedy," and those who are "always in the newspaper or on TV." Indeed, as outside opportunities for fame and fortune have expanded, some faculty garner public reputations that are most important to them and that may overshadow any internal reputation they have, with the result that the fear of a tarnished internal reputation may no longer serve to regulate internal conduct in the way it did in the past.

Third, feminism has presented an important challenge to traditional university life. Women are still only modestly represented at the higher ranks of tenured faculty at most research institutions in the US, apart from a few fields. At the same time, in many fields, women are now much more highly represented in the student body than they were in the past (even if their teachers are still primarily men). In this context, women have been understandably concerned about the risk that they will come out on the short end in the exercise of the judging and in loco parentis roles by senior male faculty.

Fourth, universities themselves seem much more caught up in competition with each other - for funding, for faculty, and for students. Of course, universities have long competed with each other, but over the past thirty years the competition appears to have become much stronger. With that change, administrators appear to be paying much more attention to things like ratings (and, in the case of public institutions, to the attitudes of state political leaders who control university funding). This competition has brought with it a great fear among administrators of the possible

16 See generally David L. Kirp, Shakespeare, Einstein, and the Bottom Line: The Marketing of Higher Education (2003). 
harm that can come to the institution from bad publicity about faculty misconduct or even appearances of (or mere charges of) faculty misconduct. Indeed, even if university insiders are confident that faculty members with conflicting interests are actually behaving in ways that are altogether consistent with their faculty roles, the administrators may be concerned that perceptions of outsiders are different. Hence, they may conclude that eliminating potential conflicts is better for the institution than trying to convince others that their faculty members are in fact behaving properly. Moreover, because of negative publicity that may accompany the exposure of conflict of interest-based misconduct, administrators will often want $e x$ post punishments handled in a "hush-hush" way. But that, in turn, probably undermines the deterrent effect of such punishment, thereby making ex ante controls, abstention, and disclosure requirements all the more appealing.

Finally, it is worth noting that many faculty members themselves have become eager for clear rules as to what is and what is not allowed. Some of them are untrusting of vague discretionary after-the-fact processes run by administrators, in which faculty fear being railroaded out of a job, tenure notwithstanding, for conduct that was not obviously inappropriate. While the regulatory web in which faculty members increasingly find themselves may be aggravating, at least on certain matters they have a clearer understanding of where the boundaries are (e.g., as to how much consulting they can do, as to which students they may date, as to what they have to disclose when they apply for research funding, etc.). Indeed, in some settings, new ex ante regulatory arrangements may be viewed as a win-win solution for faculty and the university; for example, with the support of the university's technology transfer department, faculty may be urged to commercially develop their discoveries on a royalty-sharing basis with the university.

In a similar vein, both faculty and university administrators seem eager that, to the extent possible, conflict of interest problems be handled within the university and not become subject to outside adjudication such as through civil lawsuits, criminal prosecutions, or independent administrative proceedings. This is at least partly because both sides generally believe that faculty peers and administrators, who themselves have traditionally been drawn from faculty ranks, are best positioned to decide whether an impropriety has occurred and what problems should be headed off in advance. To be sure, certain matters occasionally wind up before outside bodies (as, for example, when a faculty member has claimed to be the victim of gender or race discrimination in the judging process). Nonetheless, it seems clear that retaining university control over conflict of interest issues is furthered by the very existence of formalized internal university processes.

In sum, in this very different setting in which we find ourselves today, as 
contrasted with thirty years ago, it should not be surprising that universities have adopted proactive policies for dealing with possible conflict of interest problems before they arise. Moreover, as noted already, many of the UC policies described earlier in fact have come about in reaction to individual events of seeming infidelity to the faculty role. Hence, at UC at least, the adoption of new faculty regulation is perhaps best understood as a responsive strategy of trying to prevent something undesirable from happening again especially not on the "watch" of the administrators who had to deal with an earlier controversy. But once conflict of interest regulation is put into effect, it is not likely to be removed. And so, as new crises lead to the adoption of new measures, the regulatory regime becomes thicker and thicker.

Some analysts and scholars bemoan the growth of regulation in various sectors of the general economy and long for a return to days in which market pressures and the threat of civil liability were the basic tools society relied upon to rein in socially unacceptable conduct by enterprises. So, too, surely there are some university faculty who wish for a return to a system of much simpler management of the risks associated with faculty conflicts of interest. One argument on their side, not to be ignored, is that too much regulation may undermine, and thereby waste, the substantial benefits that have traditionally come from relying on faculty to police themselves simply because their commitment to traditional faculty roles was widely understood as central to their own identity.

Yet, for now, it is naive to imagine a return to those earlier days. If nothing else, deregulation generally has been getting a bad name of late. Moreover, those with vested interests in maintaining the regulatory regimes that universities have adopted will be difficult to dislodge. Furthermore, at least some of the new regulation of faculty conflicts of interest is probably quite a good idea. After all, in a similar vein, many believe that the securities markets, for example, work better with regimes of complicated regulation in place that require disclosure and abstention and that rule out certain actions as a way to reduce the conflict of interest problem.

Or consider, in more detail, the problem of trying to assure that witnesses who testify in court are honest in what they say. Both eyewitnesses, who are asked to report as to what they saw (or heard), and expert witnesses (say, firearms or fingerprint experts), who are asked to investigate and then tell what happened, are placed in a truth-telling role that is somewhat analogous to the truth-telling role of university faculty members.

But, like faculty, courtroom witnesses may have conflicts of interest. Some may have close relationships with parties to the litigation and, hence, may be eager to influence the outcome, regardless of whether it is based on the truth. Some may have career opportunities open or close based on what 
they testify. Some may testify for a fee, and their future prospects of being used as witnesses may depend upon their testimony. For these and other reasons, there is cause to fear that not all courtroom witnesses will naturally be honest.

To foster the truthfulness of witnesses, the legal system relies upon a variety of measures. First, witnesses are subject to cross-examination, through which their credibility as tellers of the truth may be tested. Second, through the advocacy system, the other side may put on the stand competing eyewitnesses and experts, who tell a different story and whose versions of what happened may be more convincing than those of the initial witnesses. We then rely upon independent finders of fact (usually juries in the American system, but sometimes judges) to make the credibility judgment as to the contending versions of the truth. Third, witnesses are cautioned that they must tell the truth, are sworn to tell the truth, and are at risk of possible criminal punishment for perjury if they are not honest (although this sanction is rarely invoked). Fourth, because testimony in court is public, both those in the courtroom and the public generally, via media accounts of testimony, are able to know what witnesses swear is the truth. Because one's reputation may be importantly influenced by how others perceive one's courtroom testimony, this may indirectly help assure the truthfulness of witnesses. In addition, expert witnesses must be "qualified" before they are allowed to testify, and this usually means demonstrating professional standing, which, in turn, may help assure that the witness has at least somewhat embraced professional norms of truth-telling.

This analogy shows that society draws upon a variety of social control mechanisms in the effort to overcome conflicts of interest problems that may otherwise undermine truth-telling by witnesses. In this respect, the courtroom witness example provides further evidence that the best way of dealing with the range of faculty conflict of interest problems is almost surely with a package of regulatory solutions as well.

Of course, when closely looking at the parts of the package, one is entitled to question whether the specific solutions that have been adopted for particular problems are the wisest. For example, in a specific instance, why require disclosure rather than either abstention or conflict-avoiding behavior? But to address that topic would require a one-by-one appraisal of regulatory choices, and that is beyond the reach of this essay. For now, the goal has simply been to provide an analytically thematic taxonomy of faculty roles, conflicts of interest, and conflict control mechanisms and to provide some insight into why great research universities like the University of California have, in recent years, adopted an increasingly complex set of conflict of interest controls. 
HeinOnline -- 6 Theoretical Inq. L. 2762005 